\title{
Pharmacokinetics of Micafungin in Adult Patients with Invasive Candidiasis and Candidemia*
}

\author{
Nasrullah A. Undre ${ }^{1}$, Paul Stevenson ${ }^{2}$, Ernst-Rüdiger Kuse ${ }^{3}$, Ignace Demeyer ${ }^{4}$ \\ ${ }^{1}$ Astellas Pharma Europe Ltd., Staines-upon-Thames, UK \\ ${ }^{2}$ Formerly of Astellas Pharma GmbH Munich, Munich, Germany \\ ${ }^{3}$ Medizinische Hochschule Hannover, Hannover, Germany \\ ${ }^{4}$ Onze Lieve Vrouw Ziekenhuis, Aalst, Belgium \\ Email: nas.undre@eu.astellas.com
}

Received July 9, 2012; revised August 11, 2012; accepted August 20, 2012

\begin{abstract}
Micafungin is an efficacious and well-tolerated echinocandin with in vitro and in vivo activity against a broad range of Candida species. The objective of this randomized, double-blind study was to examine the pharmacokinetic parameters of micafungin and its metabolites in a subset of adult patients with invasive candidiasis or candidemia. The study was conducted at 27 sites in four countries, including eight in Europe. Micafungin $100 \mathrm{mg} /$ day or liposomal amphotericin B $3 \mathrm{mg} / \mathrm{kg} / \mathrm{day}$ were administered once daily as a 1-hour infusion in a blinded manner. The minimum duration of therapy was 14 days. To define plasma analyte (micafungin and metabolites) concentration-time profiles, serial blood samples were collected after the first dose (Day 1), and at the end of therapy (EOT). For patients who received treatment for longer than 2 weeks, an additional profile was obtained during Week 2. To determine plasma trough analyte concentrations, blood samples were collected immediately prior to dosing on Day 2, Week 2, and EOT. In 20 evaluable, micafungin-treated patients, plasma micafungin concentrations peaked at completion of the 1-hour infusion and then declined biexponentially. Plasma concentrations of the micafungin metabolites (M-1, M-2, and M-5) remained low $(<1 \mu \mathrm{g} / \mathrm{mL})$ throughout the study. The mean half-life and clearance of micafungin were largely unchanged with repeated dosing up to 28 days, and no evidence of micafungin accumulation was observed. These data provide further support for the predictability of micafungin pharmacokinetics in adult patients with invasive candidiasis and candidemia.
\end{abstract}

Keywords: Micafungin; Pharmacokinetics; Invasive Candidiasis; Candidemia

\section{Introduction}

Invasive candidiasis and candidemia are of increasing concern in hospitals worldwide since they are a major cause of morbidity and mortality [1-3]. Reported mortality rates for Candida infections range from $10 \%$ to $76 \%$, depending on patient age, concomitant diseases, ongoing treatments, geographic location, and pathogen species [410]. Candida albicans remains the most common Candida species isolated; however, the incidence of invasive candidiasis and candidemia caused by non-albicans Candida species is on the increase [3,11].

Micafungin is an echinocandin antifungal agent that inhibits the synthesis of 1,3- $\beta$-D-glucan, an essential cell wall component of many pathogenic fungi (including Candida and Aspergillus species). In vitro [12] and in vivo $[13,14]$ activity of micafungin has been reported against a broad range of Candida species, including

\footnotetext{
*A poster featuring these data was presented at the 47 th Interscience Conference on Antimicrobial Agents and Chemotherapy, Chicago, Illinois, September 17-20, 2007.
}

non-albicans Candida and fluconazole-resistant Candida species [15]. Pharmacokinetic (PK) properties of micafungin have previously been evaluated in healthy adult subjects as well as in patients [16-20]. Micafungin exhibits linear PK as the systemic exposure (area under the concentration-time curve [AUC] and maximum plasma analyte concentration $\left[\mathrm{C}_{\max }\right]$ ) is proportional to the increasing dose, both after a single dose and at steady state. A PK steady state is reached in less than 4 days [21]. The mean terminal half-life $\left(t_{1 / 2}\right)$ is in the range of $10-17$ hours [17,19]. Clearance (CL) is independent of dose and there is no evidence of systemic accumulation with repeated administration $[21,22]$. In humans, M-1 and M-2 are the primary and secondary metabolites of micafungin and are produced by the action of arylsulfatase and catechol-O-methyltransferase, respectively. Both of these metabolites are pharmacologically active and have comparable pharmacological activity [23,24]. M-5 is formed by hydroxylation at the side chain $(\omega-1$ position) of micafungin catalyzed by cytochrome P450 isozymes. M-5 
is not pharmacologically active; however, it is the major metabolite in the systemic circulation.

Liposomal amphotericin B is a polyene macrolide antibiotic that acts by damaging the fungal cell membrane. PK parameters of liposomal amphotericin B have been compared with amphotericin B deoxycholate in healthy human volunteers. The results showed triphasic plasma profiles with long terminal $t_{1 / 2}$ (liposomal amphotericin $B$, $152 \pm 116 \mathrm{~h}$; amphotericin B deoxycholate, $127 \pm 30 \mathrm{~h}$ ). Additionally, liposomal amphotericin B produced higher plasma exposures and lower volumes of distribution versus amphotericin B deoxycholate [25].

In a large, multicenter, Phase III trial in patients with confirmed invasive candidiasis or candidemia, micafungin demonstrated similar efficacy and superior tolerability compared with liposomal amphotericin B [26]. Here we report the findings of a sub-study from that trial, in which the PK parameters of micafungin and its metabolites in a subset of adult patients have been analyzed.

\section{Patients and Methods}

\subsection{Study Design and Patient Selection}

This was an analysis of patient PK data from a doubleblind, randomized, multinational, noninferiority study to evaluate and compare the efficacy and safety of micafungin versus the efficacy and safety of liposomal amphotericin B in the treatment of invasive candidiasis and candidemia (ClinicalTrials.gov identifier: NCT00106288) [26]. This PK analysis was conducted using data from patients at 27 sites in 14 countries including eight European countries (Austria, Belgium, Czech Republic, France, Germany, Poland, Spain, and United Kingdom), Australia, Brazil, India, Thailand, the United States, and South Africa. Adult patients with confirmed invasive candidiasis or candidemia were eligible for enrollment. Centers were selected on the basis of their willingness to participate in the PK part of the study. Participation in the PK part of the study was optional, and therefore, only patients who additionally consented to participate in PK were selected. Details of inclusion and exclusion criteria have been described previously [26]. Approvals of the ethics committees of the participating centers were obtained. All patients gave written informed consent for their participation.

\subsection{Treatment Regimen}

Micafungin $100 \mathrm{mg} /$ day or liposomal amphotericin B $3 \mathrm{mg} / \mathrm{kg} /$ day were administered once daily as a 1-hour infusion in a blinded manner. The minimum duration of therapy was 14 days. The maximum treatment period was 4 weeks, except for patients with chronic disseminated (hepatosplenic) candidiasis, Candida osteomyelitis, or Candida endocarditis, in which case the treatment lasted for up to 8 weeks.

\subsection{Blood Sampling Assays}

To define plasma analyte (micafungin and metabolites) concentration-time profiles, serial blood samples were collected after the first dose (Day 1), and at the end of therapy (EOT). For patients who received treatment for longer than 2 weeks, an additional profile was obtained during Week 2. During each profile, serial venous blood samples $(2 \mathrm{~mL})$ were collected at the following time points: prior to dosing ( 0 hours); at the midpoint of infusion ( 0.5 hours); at the end of infusion ( 1 hour); and at $1.5,2,3,4,6,8,12,16$, and 24 hours post-start-of infusion. For the profile at EOT, serial venous blood samples were also collected at 36, 48, 60, and 72 hours poststart-of infusion. To determine plasma trough analyte concentrations, blood samples were collected immediately prior to dosing on Day 2, Week 2, and at EOT.

\subsection{Sample Handling}

Whole venous blood was drawn into a sodium heparin Vacutainer at each time point specified. Each blood sample was mixed well by gentle inversion and refrigerated $\left(4^{\circ} \mathrm{C}\right)$. Sample processing was completed within 8 hours of collection. Samples were centrifuged in a refrigerated centrifuge $\left(4^{\circ} \mathrm{C}\right)$ for 10 minutes at $3000 \mathrm{rpm}$ to separate the plasma from the red blood cells. The plasma was divided into two equal aliquots and then transferred into two polypropylene tubes, each containing $5 \mu$ l of phosphoric acid $\left(2: 1\right.$ with $\left.\mathrm{H}_{2} \mathrm{O}\right)$. Plasma samples were frozen at $-70^{\circ} \mathrm{C}$ until shipment on dry ice to the bioanalytical laboratory.

\subsection{Assay Method}

The plasma samples for analysis of micafungin and metabolites were prepared by protein precipitation using acetonitrile. Following centrifugation, the plasma concentrations of micafungin and three of its metabolites, M-1 (catechol form), M-2 (methoxy form of M-1), and M-5 (hydroxylation at the side chain) were determined using high-performance liquid chromatography with fluorescence detection at an Astellas contract laboratory in accordance with validated procedures [27], and in compliance with the principles of Good Laboratory Practice. The lower limits of quantification of micafungin and metabolites M-1, M-2, and M-5 in plasma were all 0.05 $\mu \mathrm{g} / \mathrm{mL}$. The inter-assay precision of quality control samples analyzed throughout the study, as measured by the coefficient of variation, was less than $6 \%$ for all analyses at all concentrations. Inter-assay accuracy varied between $96.4 \%$ and $102.1 \%$. 


\subsection{Pharmacokinetic Analysis}

Patients with evaluable profiles were those where it was possible to calculate PK parameters. Only patients with two evaluable PK profiles (Day 1 and EOT) were included in the analysis. Plasma samples taken from patients who received liposomal amphotericin B were not assayed and therefore, there are no PK data for these patients.

The $\mathrm{C}_{\max }$ and time to attain $\mathrm{C}_{\max }\left(\mathrm{T}_{\max }\right)$ were determined from individual plasma analyte concentration-time profiles. Area under the plasma analyte concentration-time curves to 24 hours $\left(\mathrm{AUC}_{0-24}\right)$, to infinity $\left(\mathrm{AUC}_{0-\infty}\right)$, and to 72 hours $\left(\mathrm{AUC}_{0-72}\right)$ for the EOT profile only, were developed using the linear/logarithmic trapezoidal rule without any weighting scheme. For the determination of the analyte $t_{1 / 2}$, a minimum of three consecutive analyte concentration-time points on the terminal $\log$ /linear decline phase were used, and $t_{1 / 2}$ was calculated using the default algorithm within the WinNonlin ProVersion 4.0.1 Enterprise (Pharsight Corporation, Mountain View, California, USA). CL for micafungin only, was estimated using the following formula:

$$
\mathrm{CL}=\text { Dose/AUC }
$$

where AUC is $\mathrm{AUC}_{0-\infty}$ for Day 1 and $\mathrm{AUC}_{0-24}$ for EOT.

To evaluate micafungin accumulation, $\mathrm{AUC}_{0-\infty}$ calculated after the first dose (Day 1) was compared with $\mathrm{AUC}_{0-24}$ at Week 2 and $\mathrm{AUC}_{0-24}$ at EOT.

\section{Results}

\subsection{Patients}

In total, 101 patients were enrolled into the PK sub-study, 45 of whom were treated with micafungin. Of those, 20 micafungin-treated patients provided evaluable PK profiles and only their data were included in the PK analyses (Figure 1). Their demographic characteristics are presented in Table 1. Most patients were male and most were Caucasian. Other races were Thai (three), black (one), Asian Indian (one), mulatto (one), and Cape colored (one). The mean age of patients was 50 years (range 18 - 84 years) and the mean weight was $67 \mathrm{~kg}$ (range 48 $103 \mathrm{~kg})$.

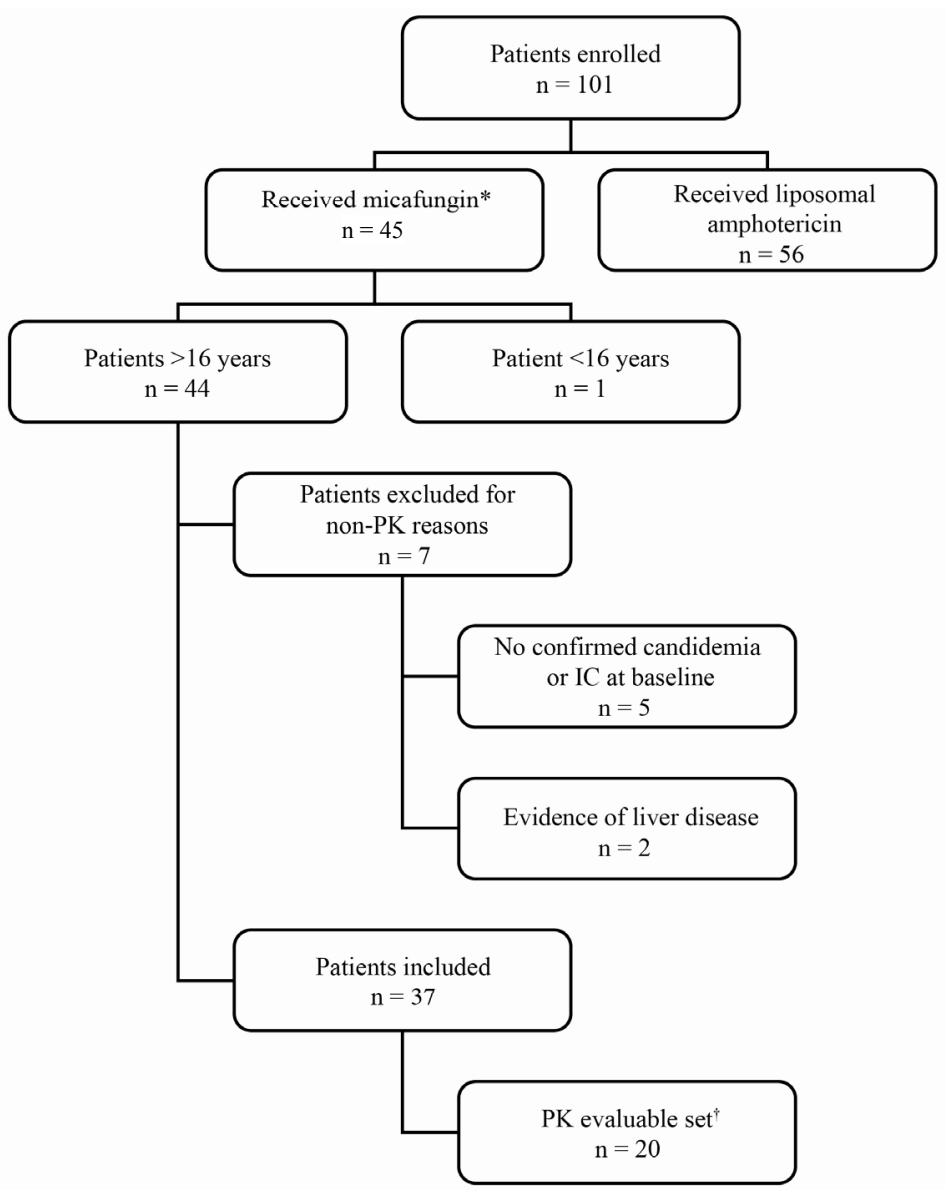

Figure 1. Patient disposition. "Patients received at least a first dose of study medication on Day 1 . $^{\dagger}$ Patients who received all doses of study medication and provided evaluable PK profiles on Day 1 and end of therapy. IC, invasive candidiasis; PK, pharmacokinetics. 
Table 1. Demographics of patients included in the pharmacokinetics analysis.

\begin{tabular}{lccc}
\hline & N & Age (years) & Weight (kg) \\
\hline All patients & 20 & $49.5 \pm 18.7$ & $67.1 \pm 14.3$ \\
Sex & & & \\
Male & 13 & $46.2 \pm 17.7$ & $66.2 \pm 12.4$ \\
Female & 7 & $54.9 \pm 20.2$ & $68.6 \pm 17.9$ \\
Race & & & \\
Caucasian & 13 & $53.9 \pm 17.3$ & $72.6 \pm 14.0$ \\
Thai & 3 & $37.8 \pm 11.0$ & $53.5 \pm 5.5$ \\
Black & 1 & 78 & 69 \\
Asian Indian & 1 & 38 & 60 \\
Mulatto & 1 & 36 & 60 \\
Cape colored & 1 & 18 & 51 \\
\hline
\end{tabular}

Data are mean \pm standard deviation.

\subsection{Pharmacokinetics}

Peak plasma micafungin concentrations occurred at the end of the 1-hour infusion. Following the end of infusion, the plasma micafungin concentrations exhibited a biexponential decline (Figures 2A-B). Plasma concentration of all metabolites remained low $(<1 \mu \mathrm{g} / \mathrm{mL})$ from the start of infusion to 24 hours after the start of infusion (Figures 2A-B).

The plasma analyte PK parameters of patients with confirmed invasive candidiasis or candidemia who were treated with micafungin are summarized in Table 2 . The mean $t_{1 / 2}$ and mean CL remained largely unchanged after repeated dosing with micafungin for 14 or 28 days.

$\mathrm{AUC}_{0-24}$ at Week 2 was $109.73 \mu \mathrm{g} \mathrm{h} / \mathrm{mL}$ and $\mathrm{AUC}_{0-24}$ at EOT was $107.41 \mu \mathrm{g} \mathrm{h} / \mathrm{mL}$. The ratios of $\mathrm{AUC}_{0-24}$ at Week 2 and EOT to $\mathrm{AUC}_{0-\infty}$ Day 1 (measure of micafungin accumulation) were 1.06 and 1.04 , respectively (Table 3).

Relative to micafungin, metabolites M-1 and M-2 accounted for only $12 \%$ and $2 \%$ of the systemic exposure at EOT, respectively. The most abundant metabolite in plasma was M-5, which accounted for $11 \%$ of the systemic exposure on Day 1 and $17 \%$ at EOT (relative to micafungin).

\section{Discussion}

This analysis characterized the PK of micafungin and its metabolites in a small subset of adult patients with confirmed invasive candidiasis or candidemia. Micafungin did not accumulate beyond a level expected for a drug with linear PK following repeated daily dosing for 14 or 28 days. CL did not significantly vary over the period of
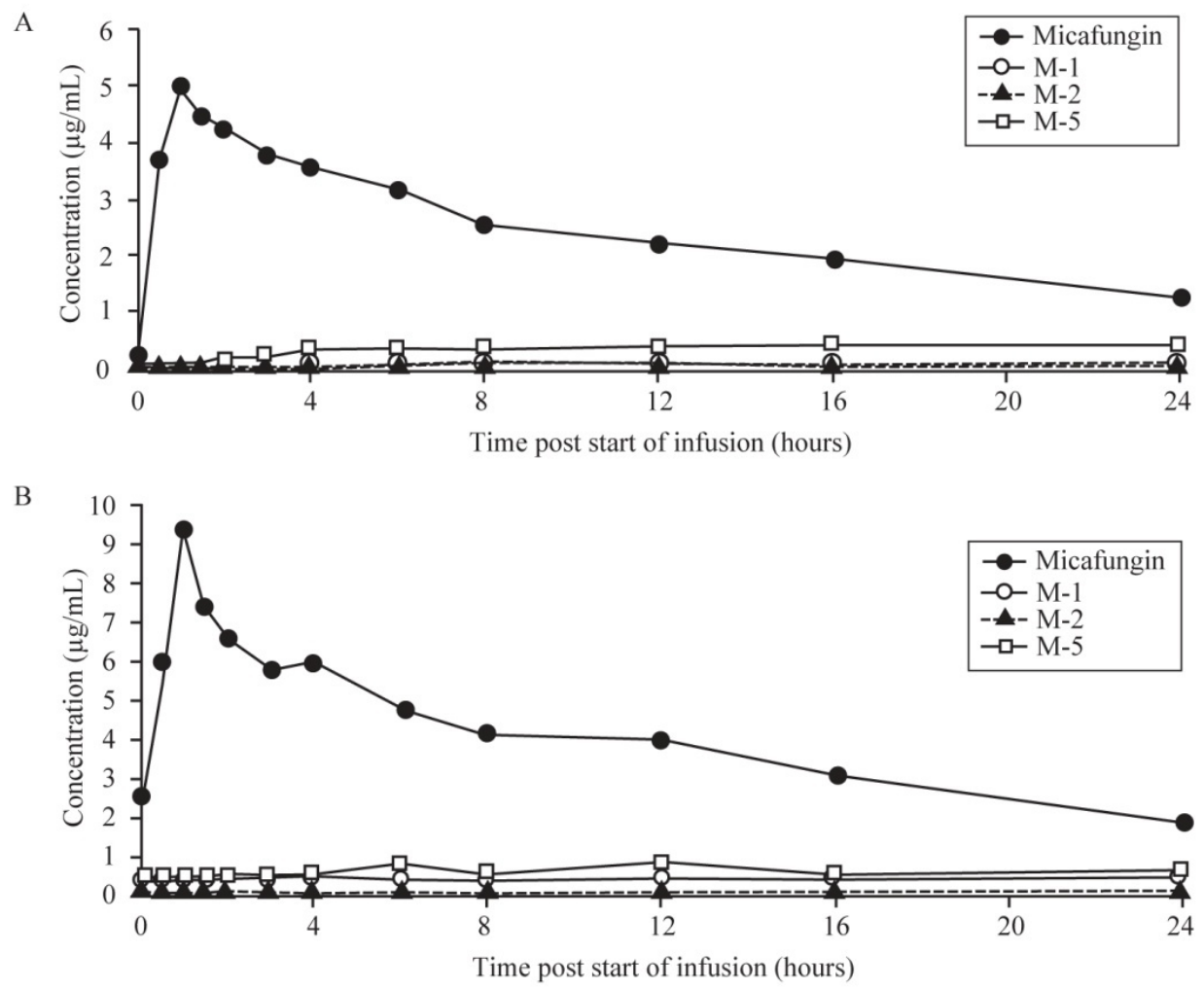

Figure 2. Mean plasma concentration-time profiles of micafungin and metabolites M-1, M-2, and M-5 on (A) Day 1 and (B) EOT. 
Table 2. Key pharmacokinetic parameters of micafungin and metabolites (M-1, M-2, and M-5) at Day 1 and EOT.

\begin{tabular}{|c|c|c|c|c|c|c|c|}
\hline & & $C_{\max }(\mu g / m L)$ & $\mathbf{T}_{\max }(\mathbf{h})$ & $\begin{array}{c}\mathrm{AUC}_{0-24} \\
(\mu \mathrm{g} \mathrm{h} / \mathrm{mL})\end{array}$ & $\begin{array}{c}\mathrm{AUC}_{0-\infty} \\
(\mu \mathrm{g} \mathrm{h} / \mathbf{m L})\end{array}$ & $\mathbf{t}_{1 / 2}(\mathrm{~h})$ & CL $(\mathrm{mL} / \mathrm{h})$ \\
\hline \multicolumn{8}{|c|}{ Micafungin } \\
\hline \multirow{2}{*}{ Day 1} & $\mathrm{~N}$ & 20 & 20 & 20 & 20 & 20 & 19 \\
\hline & Mean \pm SD & $5.69 \pm 2.15$ & $1.69 \pm 1.28$ & $56.64 \pm 30.10$ & $83.25 \pm 51.07$ & $14.47 \pm 7.01$ & $1441 \pm 728$ \\
\hline \multirow{2}{*}{ EOT } & $\mathrm{N}$ & 20 & 20 & 20 & 20 & 20 & 20 \\
\hline & Mean \pm SD & $10.05 \pm 4.37$ & $1.22 \pm 0.69$ & $97.11 \pm 28.97$ & $137.18 \pm 42.92$ & $13.37 \pm 1.99$ & $1168 \pm 561$ \\
\hline \multicolumn{8}{|l|}{ M-1 } \\
\hline \multirow{2}{*}{ Day 1} & $\mathrm{~N}$ & 20 & 15 & 20 & 1 & 1 & N/A \\
\hline & Mean \pm SD & $0.119 \pm 0.203$ & $20.03 \pm 8.43$ & $1.235 \pm 2.845$ & $39.931 *$ & $31.17^{*}$ & N/A \\
\hline \multirow{2}{*}{ EOT } & $\mathrm{N}$ & 20 & 19 & 20 & 19 & 19 & N/A \\
\hline & Mean \pm SD & $0.536 \pm 0.297$ & $13.12 \pm 11.31$ & $10.946 \pm 6.194$ & $57.380 \pm 35.414$ & $62.91 \pm 39.87$ & N/A \\
\hline \multicolumn{8}{|l|}{$\mathrm{M}-2$} \\
\hline \multirow{2}{*}{ Day 1} & $\mathrm{~N}$ & 20 & 1 & 20 & 1 & 1 & N/A \\
\hline & Mean \pm SD & $0.009 \pm 0.041$ & $6.00^{*}$ & $0.142 \pm 0.633$ & $15.586^{*}$ & $63.14^{*}$ & $\mathrm{~N} / \mathrm{A}$ \\
\hline \multirow{2}{*}{ EOT } & $\mathrm{N}$ & 20 & 16 & 20 & 13 & 13 & $\mathrm{~N} / \mathrm{A}$ \\
\hline & Mean \pm SD & $0.080 \pm 0.050$ & $23.34 \pm 20.04$ & $1.508 \pm 0.990$ & $34.472 \pm 62.170$ & $184.03 \pm 238.33$ & N/A \\
\hline \multicolumn{8}{|l|}{ M-5 } \\
\hline \multirow{2}{*}{ Day 1} & $\mathrm{~N}$ & 20 & 20 & 20 & 10 & 10 & N/A \\
\hline & Mean \pm SD & $0.449 \pm 0.356$ & $14.58 \pm 7.18$ & $7.782 \pm 6.287$ & $27.652 \pm 20.071$ & $50.53 \pm 22.84$ & N/A \\
\hline \multirow{2}{*}{ EOT } & $\mathrm{N}$ & 20 & 20 & 20 & 19 & 19 & N/A \\
\hline & Mean \pm SD & $0.861 \pm 0.792$ & $9.93 \pm 10.66$ & $15.528 \pm 11.426$ & $39.821 \pm 31.440$ & $23.11 \pm 7.05$ & N/A \\
\hline
\end{tabular}

AUC, area under the curve; $\mathrm{C}_{\max }$, maximum plasma analyte concentration; CL, clearance; EOT, end of therapy; N/A, not applicable; SD, standard deviation; $\mathrm{T}_{\max }$, time to attain $\mathrm{C}_{\max } ; \mathrm{t}_{1 / 2}$, terminal elimination half-life. $*$ Only one patient.

Table 3. Comparison of $\mathrm{AUC}_{\mathrm{inf}}$ at day 1 with $\mathrm{AUC}_{0-24}$ at week 2 and EOT.

\begin{tabular}{cccccc}
\hline $\mathrm{N}$ & $\begin{array}{c}\mathrm{AUC}_{0-\text { inf }} \text { Day 1 } \\
(\mu \mathrm{g} \mathrm{h} / \mathrm{mL})\end{array}$ & $\begin{array}{c}\mathrm{AUC}_{0-24} \text { Week 2 } \\
(\mu \mathrm{g} \mathrm{h} / \mathrm{mL})\end{array}$ & $\begin{array}{c}\mathrm{AUC}_{0-24} \mathrm{EOT} \\
(\mu \mathrm{g} \mathrm{h} / \mathrm{mL})\end{array}$ & $\begin{array}{c}\text { Ratio 1 } \\
\left(\mathrm{AUC}_{0-24} \text { week 2: } \mathrm{AUC}_{0-\infty} \text { Day 1) }\right.\end{array}$ & $\begin{array}{c}\text { Ratio 2 } \\
\left(\mathrm{AUC}_{0-24} \mathrm{EOT}_{\text {: }} \mathrm{AUC} \mathrm{C}_{0-\infty} \text { Day 1) }\right.\end{array}$ \\
\hline 8 & 103.27 & 109.73 & 107.41 & 1.06 & 1.04 \\
\hline
\end{tabular}

AUC, area under the curve; EOT, end of therapy.

the study. Systemic exposure to metabolites, M-1, M-2, and M-5 was low throughout the study. This supports the assertion that metabolites of micafungin do not contribute greatly to the therapeutic antifungal effectiveness of micafungin.

Importantly, the PK profile of micafungin in this population of adult patients with invasive candidiasis or candidemia was similar to that previously observed with the same dose in healthy adult volunteers $[16,18,19]$. Therefore, PK parameter values obtained in studies in healthy adults appear to be predictive of those in the target patient population.

A key limitation of this sub-study is the small number of patients enrolled, restricting the extent to which the results can be extended to this patient population in general. Nevertheless, the data appear to support the predictability of PK parameters of micafungin in the target population of adult patients with invasive candidiasis or candidemia.

\section{Conclusion}

These data provide further support for the predictability of micafungin pharmacokinetics in adult patients with invasive candidiasis and candidemia.

\section{Acknowledgements}

This study was sponsored by Astellas Pharma GmbH. Medical writing and editorial support was provided by Ed Parr and Sue Cooper of Envision Scientific Solutions and was supported by Astellas Pharma Inc.

\section{REFERENCES}

[1] G. Aperis, N. Myriounis, E. K. Spanakis and E. Mylonakis, "Developments in the Treatment of Candidiasis: More Choices and New Challenges," Expert Opinion on Investigational Drugs, Vol. 15, No. 11, 2006, pp. 13191336. doi:10.1517/13543784.15.11.1319

[2] A. L. Colombo, L. Thompson and J. R. Graybill, "The 
North and South of Candidemia: Issues for Latin America," Drugs of Today (Barcelona), Vol. 44, Suppl. A, 2008, pp. 1-34.

[3] M. A. Pfaller and D. J. Diekema, "Epidemiology of Invasive Candidiasis: A Persistent Public Health Problem," Clinical Microbiology Reviews, Vol. 20, No. 1, 2007, pp. 133-163. doi:10.1128/CMR.00029-06

[4] C. C. Blyth, S. C. A. Chen, M. A. Slavin, C. Serena, Q. Nguyen, D. Marriott, D. Ellis, W. Meyer and T. C. Sorrell, "Not Just Little Adults: Candidemia Epidemiology, Molecular Characterization, and Antifungal Susceptibility in Neonatal and Pediatric Patients," Pediatrics, Vol. 123, No. 5, 2009, pp. 1360-1368. doi:10.1542/peds.2008-2055

[5] B. Cao, H. Wang, L. Wu, W. J. Sun, F. Li and Y. M. Liu, "Epidemiological Study of Invasive Nosocomial Candidiasis in 2 Teaching Hospitals in Beijing [in Chinese, English Abstract]," Chinese Medical Journal, Vol. 88, No. 28, 2008, pp. 1970-1973.

[6] A. Chakrabarti, S. S. Chatterjee, K. L. Rao, M. M. Zameer, M. R. Shivaprakash, S. Singhi, R. Singh and S. C. Varma, "Recent Experience with Fungaemia: Change in Species Distribution and Azole Resistance," Scandinavian Journal of Infectious Diseases, Vol. 41, No. 4, 2009, pp. 275284. doi:10.1080/00365540902777105

[7] E. Girão, A. S. Levin, M. Basso, S. Gobara, L. B. Gomes, E. A. Medeiros and S. F. Costa, "Seven-Year Trend Analysis of Nosocomial Candidemia and Antifungal (Fluconazole and Caspofungin) Use in Intensive Care Units at a Brazilian University Hospital," Medical Mycology, Vol. 46, No. 6, 2008, pp. 581-588. doi:10.1080/13693780802004996

[8] D. L. Horn, D. Neofytos, E. J. Anaissie, J. A. Fishman, W. J. Steinbach, A. J. Olyaei, K. A. Marr, M. A. Pfaller, C.-H. Chang and K. M. Webster, "Epidemiology and Outcomes of Candidemia in 2019 Patients: Data from the Prospective Antifungal Therapy Alliance Registry," Clinical Infectious Diseases, Vol. 48, No. 12, 2009, pp. 1695-1703. doi:10.1086/599039

[9] C. Lass-Flörl, "The Changing Face of Epidemiology of Invasive Fungal Disease in Europe," Mycoses, Vol. 52, No. 3, 2009, pp. 197-205. doi:10.1111/j.1439-0507.2009.01691.x

[10] H. L. Nace, D. Horn and D. Neofytos, "Epidemiology and Outcome of Multiple-Species Candidemia at a Tertiary Care Center between 2004 and 2007," Diagnostic Microbiology and Infectious Disease, Vol. 64, No. 3, 2009, pp. 289-294. doi:10.1016/j.diagmicrobio.2009.03.010

[11] O. Leroy, J. P. Gangneux, P. Montravers, J. P. Mira, F. Gouin, J. P. Sollet, J. Carlet, J. Reynes, M. Rosenheim, B. Regnier and O. Lortholary, "Epidemiology, Management, and Risk Factors for Death of Invasive Candida Infections in Critical Care: A Multicenter, Prospective, Observational Study in France (2005-2006)," Critical Care Medicine, Vol. 37, No. 5, 2009, pp. 1612-1618. doi:10.1097/CCM.0b013e31819efac0

[12] M. A. Pfaller, L. Boyken, R. J. Hollis, J. Kroeger, S. A. Messer, S. Tendolkar and D. J. Diekema, "In Vitro Susceptibility of Invasive Isolates of Candida spp. to Anidulafungin, Caspofungin, and Micafungin: Six Years of Global
Surveillance," Journal of Clinical Microbiology, Vol. 46, No. 1, 2008, pp. 150-156. doi:10.1128/JCM.01901-07

[13] S. Maesaki, M. A. Hossain, Y. Miyazaki, K. Tomono, T. Tashiro and S. Kohno, "Efficacy of FK463, a $(1,3)-\beta$ D-Glucan Synthase Inhibitor, in Disseminated AzoleResistant Candida albicans Infection in Mice," Antimicrobial Agents and Chemotherapy, Vol. 44, No. 6, 2000, pp. 1728-1730. doi:10.1128/AAC.44.6.1728-1730.2000

[14] P. A. Warn, A. Sharp, G. Morrissey and D. W. Denning, "In Vivo Activity of Micafungin in a Persistently Neutropenic Murine Model of Disseminated Infection Caused by Candida tropicalis," Journal of Antimicrobial Chemotherapy, Vol. 50, No. 6, 2002, pp. 1071-1074. doi: $10.1093 / \mathrm{jac} / \mathrm{dkf} 247$

[15] S. A. Messer, D. J. Diekema, L. Boyken, S. Tendolkar, R. J. Hollis and M. A. Pfaller, "Activities of Micafungin against 315 Invasive Clinical Isolates of Fluconazole-Resistant Candida spp.," Journal of Clinical Microbiology, Vol. 44, No. 2, 2006, pp. 324-326. doi:10.1128/JCM.44.2.324-326.2006

[16] M. F. Hebert, H. E. Smith, T. C. Marbury, S. K. Swan, W. B. Smith, R. W. Townsend, D. Buell, J. Keirns and I. Bekersky, "Pharmacokinetics of Micafungin in Healthy Volunteers, Volunteers with Moderate Liver Disease, and Volunteers with Renal Dysfunction," Journal of Clinical Pharmacology, Vol. 45, No. 10, 2005, pp. 1145-1152. doi: $10.1177 / 0091270005279580$

[17] M. F. Hebert, R. W. Townsend, S. Austin, G. Balan, D. K. Blough, D. Buell, J. Keirns and I. Bekersky, "Concomitant Cyclosporine and Micafungin Pharmacokinetics in Healthy Volunteers," Journal of Clinical Pharmacology, Vol. 45, No. 8, 2005, pp. 954-960. doi:10.1177/0091270005278601

[18] M. F. Hebert, D. K. Blough, R. W. Townsend, M. Allison, D. Buell, J. Keirns and I. Bekersky, "Concomitant Tacrolimus and Micafungin Pharmacokinetics in Healthy Volunteers," Journal of Clinical Pharmacology, Vol. 45, No. 9, 2005, pp. 1018-1024. doi:10.1177/0091270005279274

[19] J. Hiemenz, P. Cagnoni, D. Simpson, S. Devine, N. Chao, J. Keirns, W. Lau, D. Facklam and D. Buell, "Pharmacokinetic and Maximum Tolerated Dose Study of Micafungin in Combination with Fluconazole versus Fluconazole alone for Prophylaxis of Fungal Infections in Adult Patients Undergoing a Bone Marrow or Peripheral Stem Cell Transplant," Antimicrobial Agents and Chemotherapy, Vol. 49, No. 4, 2005, pp. 1331-1336. doi:10.1128/AAC.49.4.1331-1336.2005

[20] J. Keirns, T. Sawamoto, M. Holum, D. Buell, W. Wisemandle and A. Alak, "Steady-State Pharmacokinetics of Micafungin and Voriconazole after Separate and Concomitant Dosing in Healthy Adults," Antimicrobial Agents and Chemotherapy, Vol. 51, No. 2, 2007, pp. 787-790. doi:10.1128/AAC.00673-06

[21] Astellas Pharma GmbH, "Mycamine: Summary of Product Characteristics," 2008.

http://www.ema.europa.eu/docs/en GB/document library /EPAR__Product_Information/human/000734/WC̄ 50003 1075.pdf

[22] A. H. Groll, T. Stergiopoulou, E. Roilides and T. J. Walsh, 
"Micafungin: Pharmacology, Experimental Therapeutics and Clinical Applications," Expert Opinion on Investigational Drugs, Vol. 14, No. 4, 2005, pp. 489-509. doi:10.1517/13543784.14.4.489

[23] K. Tabata, M. Katashima, A. Kawamura, A. Kagayama and S. Kohno, "Pharmacokinetics-Pharmacodynamics of Micafungin in Japanese Patients with Deep-Seated Mycosis," European Journal of Drug Metabolism and Pharmacokinetics, Vol. 31, No. 2, 2006, pp. 123-128. doi:10.1007/BF03191129

[24] K. Tabata, M. Katashima, A. Kawamura, Y. Tanigawara and K. Sunagawa, "Linear Pharmacokinetics of Micafungin and Its Active Metabolites in Japanese Pediatric Patients with Fungal Infections," Biological and Pharmaceutical Bulletin, Vol. 29, No. 8, 2006, pp. 1706-1711. doi:10.1248/bpb.29.1706

[25] I. Bekersky, R. M. Fielding, D. E. Dressler, J. W. Lee, D. N. Buell and T. J. Walsh, "Pharmacokinetics, Excretion, and Mass Balance of Liposomal Amphotericin B (AmBisome) and Amphotericin B Deoxycholate in Humans,"
Antimicrobial Agents and Chemotherapy, Vol. 46, No. 3, 2002, pp. 828-833. doi:10.1128/AAC.46.3.828-833.2002

[26] E.-R. Kuse, P. Chetchotisakd, C. A. da Cunha, M. Ruhnke, C. Barrios, D. Raghunadharao, J. S. Sekhon, A. Freire, V. Ramasubramanian, I. Demeyer, M. Nucci, A. Leelarasamee, F. Jacobs, J. Decruyenaere, D. Pittet, A. J. Ullmann, L. Ostrosky-Zeichner, O. Lortholary, S. Koblinger, H. Diekmann-Berndt and O. A. Cornely, "Micafungin versus Liposomal Amphotericin B for Candidaemia and Invasive Candidosis: A Phase III Randomised Double-Blind Trial," The Lancet, Vol. 369, No. 9572, 2007, pp. 1519-1527. doi:10.1016/S0140-6736(07)60605-9

[27] Y. Yamato, H. Kaneko, K. Tanimoto, M. Katashima, K. Ishibashi, A. Kawamura and M. Terakawa, "Simultaneous Determination of Antifungal Drug, Micafungin, and Its Two Active Metabolites in Human Plasma Using High-Performance Liquid Chromatography with Fluorescence Detection," Japanese Journal of Chemotherapy, Vol. 50, Suppl. 1, 2002, pp. 68-73. 